\title{
Análise das matrizes curriculares dos cursos de Comunicação Social com habilitação em Jorna- lismo no Brasil: um retrato da realidade nacional
}

\author{
Cristiane Hengler Corrêa Bernardo* \\ Inara Barbosa Leão**
}

\section{Resumo}

O artigo em questão é fruto de pesquisa sobre a educação jornalística e teve como objeto as matrizes curriculares de todos os cursos de Comunicação Social com habilitação em jornalismo do Brasil. O objetivo foi o de fazer um diagnóstico das estruturas curriculares do referido curso em todas as regiões do país e depois consolidar um desenho da estrutura nacional. Utilizamos como metodologia a pesquisa quantitativa e qualitativa. Nossas principais constatações foram em primeiro lugar a de que o espaço destinado aos conteúdos de Síntese/Comunicação na estrutura curricular de todas as regiões é mínimo, o que dificulta a inter-relação entre a teoria e a prática. Em segundo lugar pudemos verificar que, apesar das premissas previstas nas DCN para o curso de Comunicação Social, as realidades regionais não estão contempladas nas matrizes curriculares dos cursos. Palavras chave: Educação jornalística. Jornalismo regional. Ensino de jornalismo. Currículo de jornalismo. Comunicação social.

\footnotetext{
" Professora do Curso de Graduação em Administração, Campus Experimental de Tupã da Universidade Estadual Paulista "Júlio de Mesquita Filho" (UNESP) - Tupã, SP, Brasil. Doutora em Educação pela Universidade Federal de Mato Grosso do Sul e mestre em Comunicação Midiática pela UNESP.

E-mail: cristiane@tupa.unesp.br.

** Professora nos Cursos de Graduação em Psicologia, de Mestrado e Doutorado em Educação e Coordenadora do Programa de Pós-Graduação em PsicologiaMestrado da UFMS, Departamento de Ciências Humanas, Universidade Federal do Mato Grosso do Sul (UFMS) - Campo Grande, MS, Brasil. Doutora em Psicologia Social pela PUC e mestre em Educação pela UFMS.

E-mail: inarableao@hotmail.com.
} 


\section{Analysis of the curriculum matrices of the major in Social Communication with Journalism license in Brazil: a portrait of the national reality}

\section{Abstract}

The article is the result of a research journalistic education and aimed at building a picture of the national structure of Social Communication with Journalism license major curricula matrices in Brazil. We used the methodology of quantitative and qualitative. Our main findings were that the space for the content of Synthesis/Communication in the curricular structure throughout the country is minimal, which makes the inter-relationship between theory and practice more difficult. Secondly, we noticed that, despite the assumptions set out in the National Curriculum Guidelines for the major in Social Communication, regional realities are not included in the curriculum matrices of the majors.

Key words: Journalistic education. Regional journalism. Journalistic teaching. Journalism curriculum. Social communication.

\section{Análisis de las matrices de los cursos en Comunicación Social con licensia en Periodismo en Brasil: un retrato de la realidad nacional Resumen}

El artículo es el resultado de la investigación sobre la educación del periodismo, tuvo como objeto las matrices curriculares de todos los cursos de Comunicación Social con licensia en Periodismo en Brasil. Nuestro objetivo fue hacer un diagnóstico de las estructuras curriculares relacionadas con los cursos en todas las regiones del país y después construir una imagen de la estructura nacional. Utilizamos la metodología de la investigación cuantitativa y cualitativa. Nuestros principales resultados fueron en primer lugar que el espacio para el contenido de la Síntesis / Comunicación en la estructura curricular de todas las regiones es mínima, lo que complica la interrelación entre la teoría y la práctica. En segundo lugar observamos que, a pesar de los supuestos establecidos en el DCN para el curso de Comunicación Social, las realidades regionales no están incluidas en las matrices de los cursos.

Palabras clave: Educación del periodismo. La enseñanza del periodismo. Periodismo regional. Programas de estudios de periodismo. Medios de comunicación.

\section{Introdução}

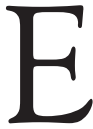

ste artigo teve origem em pesquisas efetuadas para a tese de doutoramento "Educação Jornalística: entre a cruz da academia e a espada do mercado" defendida junto ao Programa 
de Educação da Universidade Federal do Mato Grosso do Sul, em 2010. Os dados levantados e a análise efetuada não configuram parte integrante da referida tese, pois a pesquisa, pela dimensão obtida, tornou-se um projeto independente da própria tese. Os resultados obtidos, que partiram da questão de pesquisa - como estão estruturados os cursos de comunicação social com habilitação em jornalismo no Brasil - permitem a visualização do cenário das estruturas dos cursos de Comunicação Social com habilitação em Jornalismo ${ }^{1}$ em todo o país.

Por meio de uma análise quantitativa e qualitativa, realizada em levantamento estatístico das matrizes curriculares da habilitação em Jornalismo das Instituições de Ensino Superior, IESs, brasileiras, pudemos transferir (referendando ou refutando) afirmações do senso comum para o campo científico e, assim, oferecer argumentos que possibilitem uma consciência crítica sobre a estrutura curricular dos referidos cursos.

Todavia, apenas os conteúdos oferecidos pelas matrizes curriculares e os documentos da área, em específico as Diretrizes Curriculares para os Cursos de Comunicação ${ }^{2}, \mathrm{DCN}$, isoladamente não sustentariam, por si, a pesquisa a qual nos propusemos. Diante de tal fato, é imprescindível referendar que os conteúdos estudados para a elaboração da tese de doutoramento foram fundamentais para as reflexões que apresentamos neste artigo, com destaque para Coelho Sobrinho (2001); Marques de Mello (1992; 1991; 1986; 1974); Moura (2002); Meditsch (2007); Schuch (2002); Silva (1991); Valverde (2006); Zanetin (2006).

A metodologia para a coleta de dados partiu de acessos ao Portal do Siedsup ${ }^{3}$, consultando, por região, todos os cursos de jornalismo do país. O levantamento indicou a existência de 375 cursos, distribuídos entre as cinco regiões do Brasil da seguinte forma: 25 cursos no Norte; 62 no Nordeste; 31 no Centro Oeste;

\footnotetext{
${ }^{1}$ A partir de agora vamos passar a nos referir ao curso de comunicação social com habilitação em jornalismo como curso de jornalismo.

2 Parecer CNE/CES nํ 492, de 03 de abril de 2001 Aprova as Diretrizes Curriculares Nacionais dos cursos de Arquivologia, Biblioteconomia, Ciências Sociais - Antropologia, Ciência Política e Sociologia, Comunicação Social, Filosofia, Geografia, História, Letras, Museologia e Serviço Social.

${ }^{3}$ Site : www.educacaosuperior.inep.gov.br/funcional/busca_curso.stm
} 
194 cursos no Sudeste e 61 no Sul. A consulta não se restringiu a esta fonte, uma vez que no Portal do Siedsup só estão disponibilizados alguns dados do curso e da IES. Fica aqui, inclusive, a sugestão para que o Instituto Nacional de Educação e Pesquisa, INEP, acrescente, às informações disponíveis na página, a matriz curricular dos cursos.

Após o diagnóstico dos cursos existentes no Portal, enfrentamos enorme dificuldade para a coleta dos dados, pois tivemos que acessar o site de cada IES, os 375 portais, e procurar no conteúdo dos mesmos as matrizes curriculares a serem analisadas. Outra constatação importante a ser destacada é a de que, apesar da determinação do Ministério da Educação, MEC, de que as matrizes curriculares têm de estarem disponibilizadas no site institucional, apenas 204 matrizes eram públicas.

A próxima etapa consistiu em separar destas matrizes apenas as que apresentavam disponíveis a carga horária destinada a cada disciplina, pois esta era necessária para a nossa análise qualitativa na distribuição dos conteúdos teóricos e práticos e de que forma os mesmos interagiam, caso essa interação ocorresse. Desprezamos também as matrizes curriculares que apareciam iguais em IESs pertencentes ao mesmo grupo empresarial em diferentes campi. Estas foram consideradas uma única vez por região, como se fossem um curso único. Assim, o número foi reduzido para 153 cursos.

Em números finais de análise, após todos esses filtros, ficamos no Nordeste com 30 cursos; no Sudeste, com 55 cursos; no Sul, com 38 cursos; no Centro-Oeste, com 12; e no Nordeste, com 18 cursos, representando, no total, uma cobertura de $40.8 \%$ dos cursos de Jornalismo no país.

Partimos então para a classificação das disciplinas em blocos cujas nomenclaturas das disciplinas eram comuns à maioria das matrizes analisadas. Com os blocos definidos quantificamos se as disciplinas estavam presentes ou ausentes na estrutura curricular e, no caso de existirem, quantificamos sua carga horária. Com esses elementos em mãos, definimos os blocos partindo da maior incidência das nomenclaturas das disciplinas nas 153 matrizes e criamos o modelo utilizado que segue: no Bloco 1, constaram as disciplinas de Filosofia; Filosofia e Ética; Filosofia da Comunicação; 
Humanidades; Ausente (o termo ausente vai se referir à categoria que não apresentava nenhuma das disciplinas mencionadas). No Bloco 2, estão incluídas as disciplinas de Sociologia; Sociologia da Comunicação; Sociologia e Antropologia; Ambas (Sociologia e Sociologia da Comunicação); Humanidades; Ausente. No Bloco 3, temos Antropologia; Antropologia Cultural; Humanidades; Ausente. Bloco 4: Psicologia; Psicologia da Comunicação; Ambas (Psicologia Geral e da Comunicação); Ausente. O Bloco 5 foi composto por Economia Geral; Economia Regional; Economia e Política; Ausente. No Bloco 6, as disciplinas integrantes são: Ciência Política; Ausente. Para integrar o Bloco 7, temos Realidade Socioeconômica/Política; Realidade Regional; Realidade Geral e Regional; Ausente. O Bloco 8 foi composto pelas disciplinas ligadas à abordagem cultural, quais sejam: Cultura Geral; Cultura Regional; Cultura Geral e Regional; Estética; Comunicação e Cultura; Ausente. No Bloco 9, constam História Geral e Brasileira; História Regional; Historia Geral e Regional; Ausente. O Bloco 10 é composto por Ética; Legislação; Legislação e Ética Juntas; Teologia e Ética; Ausente. Já o bloco 11 é composto por Historia da Arte; Ausente. O Bloco 12 comporta as disciplinas de Estatística; Estatística e Matemática; Estatística e Opinião Pública; Ausente. Informática; Informática e Multimídia; Ausente, integram o bloco 13. No Bloco 14, constam Geografia Geral/Brasileira; Geografia Regional; Geopolítica; Ausente. O Bloco 15 inclui as disciplinas de Língua Portuguesa; Laboratório de Texto; Ambos; Ausente. O Bloco 16 aborda a inserção dos idiomas estrangeiros e é composta por Inglês; Espanhol/Francês; Ambos; Ausente. O Bloco 17 é composto pelas disciplinas de Teoria da Comunicação; Teoria do Jornalismo; Ambos; Ausente. O Bloco 18 é integrado por Comunicação Comparada; Jornalismo Comparado; Ambos; Ausente. No Bloco 19, colocamos as disciplinas introdutórias conceituais da profissão, são elas: Introdução ao Jornalismo; Introdução à Comunicação/Mídia; Ambos; Ausente. O Bloco 20 é composto pelos aspectos históricos e integram esse bloco as disciplinas deHistória da Comunicação; História da Imprensa; História do Jornalismo; Historia do Jornalismo e da Comunicação; Ausente. No Bloco 21 registramos Mídias Alternativas/Novas Mídias; Novas Tecnologias em Comunicação. Ambas; Ausente. O Bloco 22 conta 
com Metodologia da Pesquisa Científica; Metodologia da Pesquisa em Comunicação/Jornalismo; Ambos; Ausente. No Bloco 23, temos Semiótica; Ausente. O Bloco 24 é composto pelas disciplinas de Comunicação Visual; Fotografia; Fotojornalismo; Ambos; Ausente. Editoração Eletrônica; Planejamento Gráfico; Ambos; Ausente, compõem o Bloco 25. Já o Bloco 26 têm as disciplinas de Técnicas de Reportagem e Entrevista; Ausente. No Bloco 27 se enquadram Assessoria de Imprensa; Assessoria de Comunicação; Ambos; Ausente. O Bloco 28 integra Jornalismo Impresso; Ausente. No Bloco, 29 encontramos Edição; Ausente. O Bloco 30 é integrado pelas disciplinas de Redação Jornalística; Ausente. No Bloco 31, temos Radiojornalismo; Ausente. O Bloco 32 é composto por Jornal Laboratório; Ausente. O Bloco 33 abarca Telejornalismo; Ausente. O Bloco 34 é composto por Jornalismo Online/Digital; Ausente. No Bloco 35, incluímos as áreas especializadas e o bloco foi composto pelas disciplinas de Jornalismo Ambiental; Jornalismo Científico; Jornalismo Econômico; Jornalismo Esportivo; Jornalismo Especializado; Jornalismo Cultural; Jornalismo Comunitário; Jornalismo Internacional; Jornalismo ONG; duas ou mais especializações (quando apresentavam mais de uma especialização); Ausente. $\mathrm{O}$ Bloco 36 é integrado por Agência de Notícia; Ausente. O Bloco 37 engloba a gestão da comunicação e é integrado pelas disciplinas de Administração Geral; Administração em Jornalismo/Comunicação; Planejamento Estratégico/Empreendedorismo; Ausente. O Bloco 38 é composto por Marketing; Ausente. E por fim o Bloco 39 inclui Projeto Experimental; Estágio Supervisionado; Ausente.

Além da divisão em nomenclaturas, cada um dos blocos também foi dividido em classificações por cargas horárias (de hora/ aula), tendo sido definidos os seguintes intervalos: de até 36 horas/ aula; de 37 horas/aula até 59 horas/aula; de 60 a 79 horas/aula; de 80 a 99 horas/aula e acima de 100 horas-aula. A divisão dos intervalos teve como base a heterogeneidade das cargas horárias existentes nas diversas regiões do país.

As disciplinas que não constavam nas matrizes curriculares eram computadas no item "Ausente" e, na tabulação para que aparecessem como "Ausentes" deveriam computar um número de registros superior a todas as demais alternativas do bloco somadas. 
Já as disciplinas que não constavam em nenhum dos blocos foram classificadas conforme sua aparição num último bloco denominado de "outras" e consideradas para análise, em cada região, os dois maiores registros. Segue a classificação: Bloco 40 - Outras: Políticas públicas em comunicação; Técnicas de oratória; História em quadrinhos; Documentário; Metodologia da pesquisa em RP; Introdução às RP/PP; Processo negocial; Produção de artigo científico; Cultura religiosa; Crítica de mídia; Campo profissional; Assessoria política; Media training; Mídia e ciência; Cinema; Comunicação popular; Comunicação alagoana; Consultoria metodológica; Sistemas internacionais de comunicação; Produção em mídia; Cibercultura; Seminários em comunicação/tópicos especiais; Design de notícias; Comunicação e educação; Criatividade e inovação; Meio ambiente e sociedade; Lógica; Relações públicas e humanas; Comunicação e cidadania; Meio ambiente e turismo; Estudos da recepção; Narrativa ficcional; Folclore brasileiro; Mundo contemporâneo; Atendimento; Libras; Análise do discurso; Hipermídia; Teoria literária; Locução; Produção de eventos; Empresa simulada; Comportamento do consumidor; Literatura; Ética cristã; Cristianismo; O humano e o fenômeno religioso; Retórica e argumentação; Iniciação a prática docente; Linguagem musical; Teledramaturgia; Organização de eventos; Práticas desportivas; História das ideias; Desafios das micro e pequenas empresas; Responsabilidade social; Problemas do homem contemporâneo; Técnicas em arte final; Estágio em saúde da família e da comunidade; Ausente.

Após a apuração quantitativa, partimos para a análise qualitativa e, para tal, utilizamos a classificação criada pelo chamado grupo de Bloom ${ }^{4}$ e usada pelo Departamento de Comunicação da Escola de Comunicação e Artes da USP - ECA ${ }^{5}$ para a discussão sobre o projeto político pedagógico do curso. A classificação foi adaptada para esta análise e dividiu as disciplinas em grupos de Conhecimentos e Compreensão; Aplicação e Análise/Avaliação e Síntese/Comunicação.

\footnotetext{
${ }^{4}$ Em 1951, Benjamin S. Bloom e outros psicólogos dos EUA, como Max D. Engelhart, Edwar J. Furst, Walker H.Hill e David R. Krathwohl, desenvolveram um método de avaliação curricular denominado "Taxionomia de Objetivos Educacionais", abordando os domínios cognitivo e afetivo da educação.

${ }^{5}$ Disponível em http://www.eca.usp.br/prof/moran/uber.htm
} 
O conceito criado pelo grupo de Bloom (1974), basicamente, propõem que os currículos sejam organizados de forma a haver uma lógica no encadeamento das disciplinas e do processo de aprendizagem. A ideia é a de que um conteúdo conduza a outro, em uma ordem crescente e gradual, que se origina no mais simples e vai até o mais complexo, sendo composta por seis etapas inter-relacionas: conhecimento, compreensão, aplicação, análise, avaliação e síntese.

A estrutura curricular que se imagina ideal a partir do conceito de Bloom (1974) é discutida pelos autores Campos; Rocha (2011).

Infelizmente, porém, nem todos os currículos de Jornalismo estão estruturados de tal modo que no primeiro termo os estudantes possam ter disciplinas que favoreçam o conhecimento, levando-se em conta as deficiências do Ensino Fundamental e também do Ensino Médio, principalmente, a falta de reflexão e de pensamento crítico. Só na sequência é que deveriam vir as disciplinas voltadas à compreensão dos fenômenos, pois é clássico que só quem conhece pode compreender. Vencidas essas duas etapas, os currículos poderiam partir para as disciplinas laboratoriais, a partir das quais o aluno aplicaria o que aprendeu, realizando a necessária experimentação nos mais diferentes produtos. Auxiliado pelas disciplinas dessa fase, o jovem estaria pronto para aprender a analisar o que produziu, desenvolvendo, também, uma visão de conjunto sobre a realidade à sua volta. Agora ele estaria apto a sintetizar o conhecimento, incorporando sua visão de mundo, seu olhar próprio, sua construção crítica. No fim do curso, então, sim, o estudante passaria por disciplinas que favoreceriam uma avaliação do todo aprendido, percebendo a complexidade dos sistemas de comunicação e do mundo em geral, tomando noção de que é preciso gerir o processo, gerir, inclusive, o próprio texto, o próprio espaço, dentro da engrenagem comunicativa, dentro das equipes de trabalho, percebendo o todo, o conjunto, as interdependências inerentes ao processo (CAMPOS; ROCHA, 2011, p.17-18).

Com base nesse conceito entendemos que, para esta análise, o grupo que envolve Conhecimentos e Compreensão deveria ser composto por conteúdos que abordassem a história da profissão; a história da comunicação e de suas interfaces culturais; os conhecimentos teóricos da área de comunicação; as políticas voltadas para a comunicação, assim como para o conhecimento e a compreensão, de forma mais amplos, voltados para aspectos 
políticos, econômicos, históricos e culturais da sociedade em que a profissão se desenvolve.

Assim sendo, incluímos nesse primeiro grupo as seguintes disciplinas: História do Jornalismo, História da Arte, Teoria da Comunicação/Jornalismo, Legislação e ética do Jornalismo, Introdução à Informática, Introdução ao Jornalismo, Artes Gráficas, Sistemas de Informação, Economia, Introdução à Pesquisa Científica, História, Ciências Políticas, Literatura, Semiótica, Administração de Empresas Jornalísticas, Técnicas de fotografia, Língua Portuguesa, Língua Estrangeira, Redação Jornalística, Cultura, Sistemas Políticos Comparados, Técnicas Radiofônicas, Técnicas de Televisão, Técnicas de Jornalismo Online, Seminários de Atualidade Brasileira, Organização Política, História das Doutrinas Políticas, Filosofia da Comunicação, Sociologia da Comunicação, Antropologia Cultural e Psicologia da Comunicação.

No bloco de Aplicação e Análise/Avaliação, incluímos as disciplinas de caráter profissionalizante e, portanto, mais prático. Nessa fase também haveria uma reflexão com o objetivo analítico sobre o que foi apreendido e sobre os produtos confeccionados pelos acadêmicos em suas atividades laboratoriais. Compondo esse grupo temos as disciplinas de Planejamento Gráfico e Editoração, Metodologia de Pesquisa em Comunicação, Agências de Notícias, Fotojornalismo, Jornal Impresso, Jornal Laboratório, Radiojornalismo, Telejornalismo, Assessoria de Imprensa/Comunicação, Novas Mídias/Tecnologias, Edição, Jornalismo Online, Jornalismo Especializado e Estágio Supervisionado.

Por fim, para o grupo de Síntese/Comunicação, constatamos que as matrizes curriculares analisadas destinavam apenas a disciplina de Trabalho de Conclusão de Curso ou Projeto Experimental, para o que entendemos como sendo o momento de integração entre teoria e prática, ou seja, entre o conhecimento e compreensão e a aplicação e análise/avaliação.

Diante desse entendimento apresentamos esquematicamente o método de correlação já descrito anteriormente neste artigo, para que possamos visualizar graficamente como se dá essa associação. 


\section{Método de correlação}

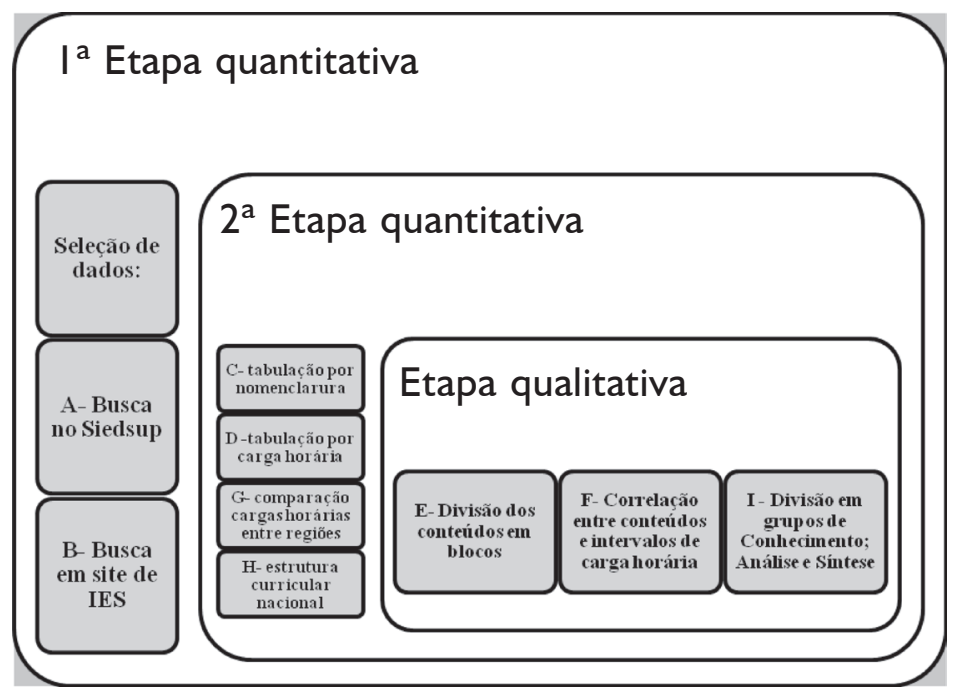

Constatações: diferentes realidades em cada região

Nossa pesquisa, em virtude do que preconizam as Diretrizes Curriculares Nacionais, DCN, com relação ao curso atender às necessidades regionais, foi realizada com dados de cada uma das regiões brasileiras e depois consolidada em uma análise nacional que configura cada realidade.

\section{Região Norte: menor concentração de cursos e menor carga horária}

A região Norte do país registra a menor concentração de cursos de jornalismo, sendo 25 cursos e 18 estruturas analisadas.

De acordo com as DCN o número mínimo de horas-aula para as estruturas curriculares do curso de jornalismo é de 2700 horas/aula, sendo que nesse cômputo podem já estar incluídas as atividades complementares, estágio supervisionado e projeto experimental. Ao todo 17 matrizes curriculares da região Norte obedecem a este mínimo. Apenas uma Universidade de Roraima oferece uma carga horária abaixo do mínimo - 1140 horas/aula. 
A média de carga horária registrada na região foi de 2300 horas/aula, a menor do país, e estão distribuídas em 1120 horas-aula para as disciplinas essencialmente teóricas, 1080 horas-aula às práticas, incluindo a elaboração do Projeto Experimental e as Atividades Complementares. Nenhum curso do Norte registrou estágio supervisionado em suas matrizes e apenas um curso oferece jornal laboratório como disciplina.

A ausência do bloco de história nos chama atenção, pois não há nos cursos de jornalismo da região Norte um aprofundamento em história geral, brasileira ou regional. A língua estrangeira também foi totalmente descartada das matrizes dessa região, não tendo sido registrada em nenhum curso. Também falta espaço para novas tecnologias da comunicação, assim como para as mídias alternativas, estas últimas um recurso pouco explorado pelos cursos de jornalismo e que poderão configurar uma excelente alternativa para um jornalismo mais voltado para a sua função social, como reflete Bernardo (2010). Apenas cinco matrizes registraram disciplinas nesse bloco, com uma carga horária média de 60 horas-aula.

A disciplina de semiótica também não integra 99\% das matrizes do Norte. Na parte prática dos cursos da região Norte, verificamos a ausência das disciplinas de técnicas de reportagem e entrevista e de edição, conteúdos estes, que podem estar contemplados em outras disciplinas, e se estiverem podem prejudicar os conteúdos das disciplinas responsáveis pela absorção desse déficit. Agência de notícias e marketing, também seguindo uma tendência que veremos nas demais regiões, não aparecem no Norte, sendo que a primeira teve um único registro e, a segunda apenas três.

Com relação às disciplinas "outras", não constantes em nenhum bloco, e que foram registradas uma a uma conforme suas incidências, as duas que aparecem com maior ocorrência são documentário, em quatro estruturas, e políticas públicas de comunicação em duas. No caso das "outras" disciplinas percebemos que esta, no caso específico da região norte, são muito variadas, tendo quase uma disciplina diferente por curso.

Percebemos ainda uma alta concentração de carga horária na disciplina de língua portuguesa, sendo que 17 cursos têm carga horária superior a 100 horas/aula, sendo que apenas um curso da 
região Norte registra 80 horas/aula nessa disciplina. Esta tendência também poderá ser verificada em outras regiões.

$\mathrm{Na}$ análise quantitativa que divide as disciplinas em grupos de Conhecimento e Compreensão; Aplicação e Análise/Avaliação e Síntese/Comunicação não constatamos, por meio das estruturas curriculares, espaços para a inter-relação entre as disciplinas teóricas e as disciplinas práticas. Há uma verdadeira divisão; de um lado os blocos dos conteúdos mais teóricos e de outro os práticos e não há a presença de um projeto integrador entre ambos os blocos. Registro que essa afirmação é baseada apenas na análise da estrutura curricular e não no projeto político pedagógico do curso como um todo que poderá contemplar alguns instrumentos integradores que não aparecem na organização da matriz curricular.

Sistematizando esta análise classificamos as estruturas curriculares dos 18 cursos da região Norte no gráfico a seguir:

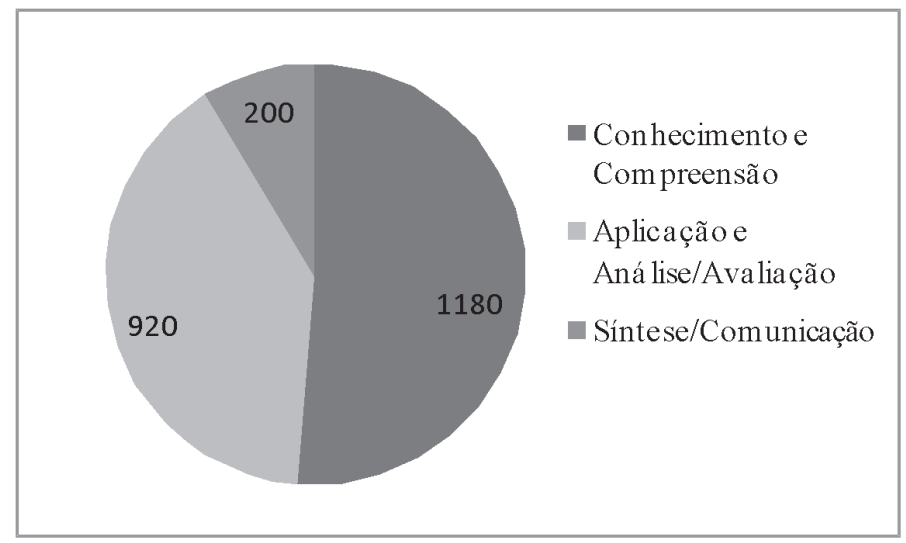

Percebe-se que há um equilíbrio entre o Conhecimento e Compreensão em relação à Aplicação e Análise/Avaliação, entretanto, muito se distanciam em equidade de conteúdo com a Síntese/Comunicação. Fica evidente a separação entre as disciplinas voltadas para o Conhecimento e Compreensão, que têm características mais teóricas e as direcionadas para a Aplicação e Análise/Avaliação, que são de naturezas mais práticas e/ou técnicas. Existe, nesse sentido, em termos de estrutura curricular, um único momento de integração entre os módulos que resultaria 
numa aproximação teoria-prática. No caso da região Norte, ela se configura por meio do Projeto de Conclusão de Curso ou Projeto Experimental, com apenas 200 horas-aula da média curricular da região que é de 2300 horas-aula, menos de 10\% da carga horária total dos conteúdos ministrados.

Região Nordeste: menor espaço para aprofundamento e maior variedade de áreas de conhecimento

Foram analisadas 30 matrizes curriculares dos 62 cursos de jornalismo da região Nordeste, apresentando uma carga horária média de 2780 horas aula.

Da região Nordeste, apenas uma universidade da Bahia registra carga horária abaixo do mínimo determinado pelas DCN. A carga horária apresentada por esta IES é de 2.625 horas-aula, todos os outros 29 cursos analisados cumprem a carga horária mínima prevista para a habilitação em Jornalismo. A carga máxima apresentada foi de 3.380 horas-aula.

A estrutura curricular da região Nordeste destina em média 1260 horas-aula para as disciplinas de caráter teórico; 1240 horas- aula para as disciplinas práticas e 280 horas-aula para o Projeto Experimental, representada na seguinte configuração:

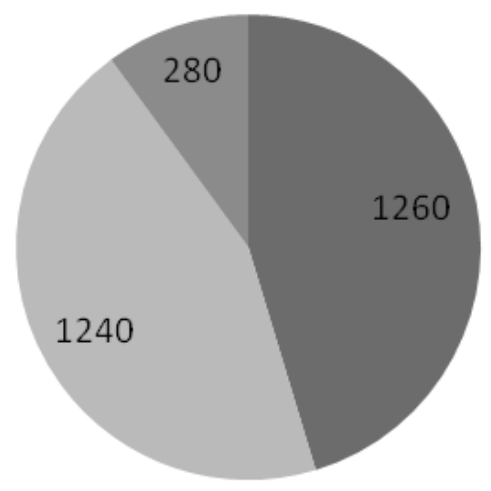

Conhecimentos e Compreensão

Aplicação e Análise/Avaliação

Sintese/Comunicação 
Da mesma forma que na região Norte, é perceptível o equilíbrio quantitativo existente entre os grupos de Conhecimentos e Compreensão com o de Aplicação e Análise/Avaliação. Entretanto, o encontro de ambos só ocorre num espaço de 280 horas-aula, na elaboração do Projeto Experimental que compõe o grupo de Síntese/Comunicação.

A ausência das disciplinas de história, estatística, geografia, semiótica e língua estrangeira repete uma tendência de todas as regiões do país. No caso da região Nordeste não há, em 89\% dos casos, a disciplina de comunicação ou jornalismo comparado. As disciplinas de jornal laboratório, agência de notícias e marketing também não figuram na região Nordeste. Este também é o caso de estágio supervisionado que foi registrado em apenas quatro matrizes.

Assim como na região Norte, encontramos em "outras" a disciplina de documentário. O outro maior registro é o de seminários em comunicação/tópicos especiais em comunicação que, também seguindo uma tendência nacional, tem como principais características servir como uma verdadeira esponja dos conteúdos preconizados pelas DCN e que não foram incluídos em nenhuma outra disciplina.

Língua portuguesa e/ou laboratório de texto, no Nordeste, também tem a maior carga horária entre os conteúdos registrados. No caso da disciplina de humanidades, a carga horária registrada pela região Nordeste é menor que a da Norte. Pode-se observar que a matriz da região Norte tem maior espaço para aprofundamento ao passo que na região Nordeste há uma maior variedade de áreas de conhecimento.

As disciplinas de novas tecnologias e/ou mídias alternativas e técnicas de entrevista e reportagem encontram maior espaço na região Nordeste. A disciplina de jornalismo online, apesar de registrada nas matrizes das duas regiões, encontra maior amplitude na região Nordeste, em comparação com a Norte.

Das áreas profissionalizantes, percebemos em ambas as regiões, um espaço maior dado ao telejornalismo e ao radiojornalismo, entretanto, no Nordeste as disciplinas voltadas para o jornalismo impresso têm maior carga horária que na região Norte. 
Região Centro-Oeste: menor número de disciplinas e falta de conteúdos imprescindíveis

Dos 31 cursos da região Centro-Oeste, analisamos 12 e, são os que mais apresentam carga horária concentrada em um menor número de disciplinas, deixando de contemplar conteúdos imprescindíveis ao ensino do jornalismo.

Em média, os cursos do Centro-Oeste têm 2790 horas-aula, um número superior em 10 horas-aula ao da região Nordeste, entretanto, ao passo que esta última registrou 31 disciplinas, o Centro-Oeste apresenta, em média, 24 disciplinas. Cinco a menos ainda que a região Norte.

O curso oferecido por uma Instituição Tecnológica tem a menor carga horária - apenas 1820 horas - aula, distribuídas em três anos e fora da regulamentação do MEC no que tange a carga horária mínima e período de integralização do curso. Uma IES do Mato Grosso é a que registra a maior carga horária com 3200 horas-aula. A média encontrada nas doze matrizes analisadas foi de 2740 horas-aula.

No Centro-Oeste, as disciplinas de características mais teóricas somam apenas 750 horas-aula; 1750 horas-aula de disciplinas técnicas e/ou práticas e 240 horas-aula do Projeto Experimental. Temos os três grupos distribuídos da seguinte forma:

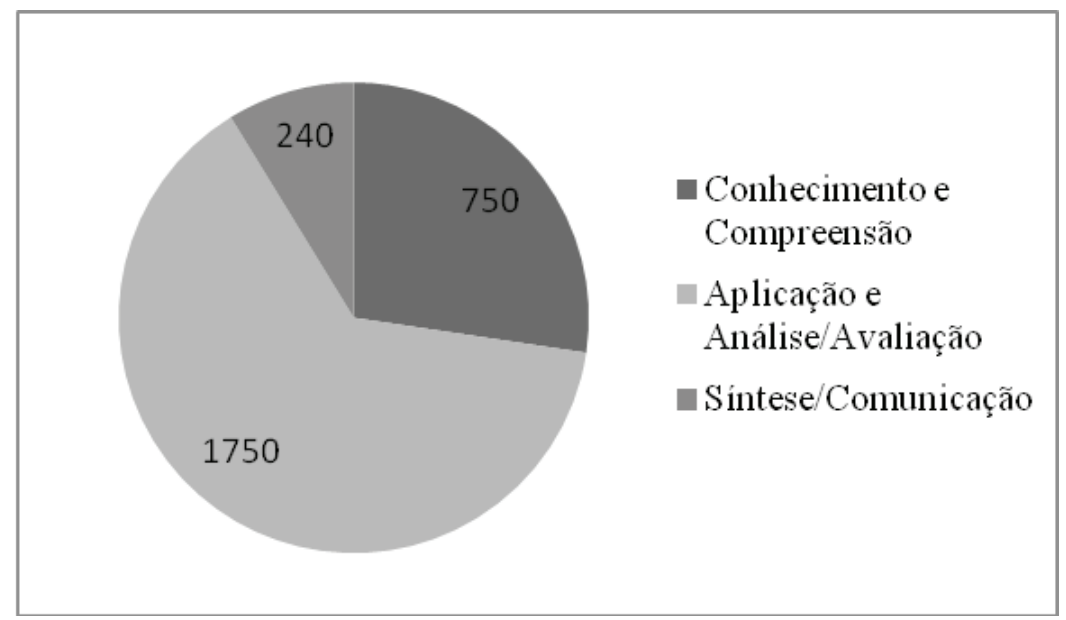


O Centro-Oeste apresenta claramente uma estrutura curricular mais voltada a conteúdos práticos. É evidente a falta de espaço para o Conhecimento e Compreensão com relação à região Norte e Nordeste. A Síntese, assim como nas demais regiões, também ficou bastante desequilibrada na distribuição dos conteúdos.

Há uma concentração de carga horária bastante acentuada nas disciplinas de fotografia e fotojornalismo, redação jornalística, radiojornalismo, telejornalismo e jornalismo impresso.

Nas "outras" disciplinas há seminários em comunicação/tópicos especiais em comunicação e surge a disciplina de criatividade e inovação, mais comum na habilitação em Publicidade e Propaganda.

Região Sudeste: maior concentração de cursos, supervalorização da área de análise/avaliação e prejuízo do Conhecimento/ Compreensão

O Sudeste é a região com a maior concentração de cursos de jornalismo, ao todo 194, sendo que analisamos 55 estruturas curriculares.

No caso da região Sudeste é ainda maior o desequilíbrio entre a carga horária destinada aos conteúdos teóricos e aos práticos. Da média de 2760 horas-aula, são destinadas aos conteúdos teóricos apenas 640 horas-aula; mais 310 horas-aula para o Projeto Experimental e 1810 horas-aula para as disciplinas práticas. Ao estabelecermos os grupos, visualizamos a seguinte situação na região sudeste:

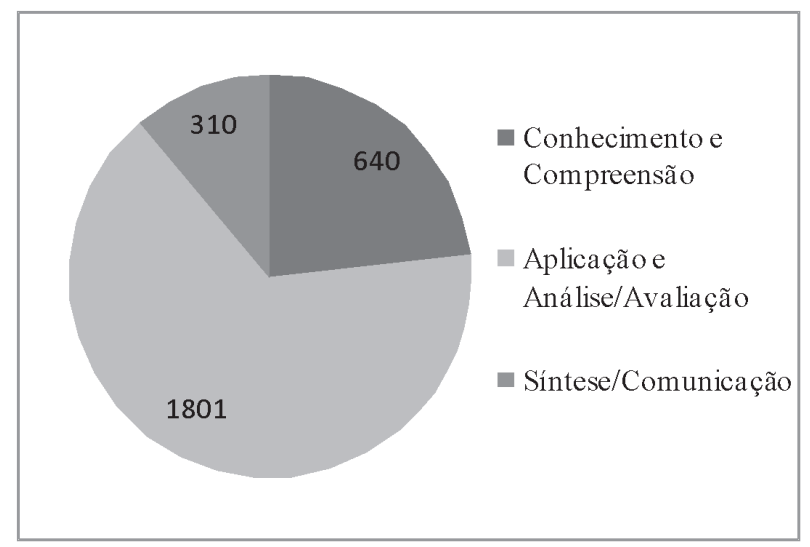


O grupo de Aplicação e Análise/Avaliação é muito superior aos demais e não deixa espaço suficiente para a reflexão dos processos comunicacionais. Aumenta a Síntese com relação às três regiões anteriores, embora de forma não significativa. Esta é representada, em $98 \%$ dos casos, apenas pelo projeto experimental. O estágio supervisionado está presente em apenas cinco estruturas, apesar do esforço do Sindicado de Jornalistas do Estado de São Paulo, o primeiro a implantar um programa de estágio oficial, e buscar a adesão das IESs. É também nesta região a maior concentração dos grandes veículos de comunicação, o que, teoricamente, representaria um grande campo para o desenvolvimento da prática pré-profissional que pode ser proporcionada por meio do estágio.

\section{Região Sul: a maior carga horária do país também sobrepõe a Aplicação em detrimento do Conhecimento/Compreensão}

Dos 61 cursos e 38 matrizes curriculares analisadas, a região Sul tem apenas 888 horas-aula destinadas às disciplinas teóricas; 280 horas-aula para o Projeto Experimental e 1722 horas-aula destinadas às práticas. Nessa região foi registrada a maior média em carga horária da estrutura curricular, 2890 horas-aula.

Há uma grande carga horária destinada à disciplina de língua portuguesa e ao contrário das outras regiões, apesar da baixa carga horária destinada à área do Conhecimento e da Compreensão, encontramos uma concentração de espaço para as teorias da comunicação e do jornalismo. Essa concentração só se repete, posteriormente, nas disciplinas de caráter mais laboratoriais como é o caso de radiojornalismo, telejornalismo e fotojornalismo. Pode- se observar a divisão no gráfico a seguir:

\section{Consolidação da Estrutura Curricular Nacional: características regionais ainda não configuram uma realidade}

As DCN recomendam que as estruturas curriculares devam fazer previsões referentes ao desenvolvimento de uma vocação regional que oriente aspectos determinados e delimitados na formação, promovendo a adequação do curso às condições socioeconômicas e culturais da região em que estiver localizada a Instituição e valorizando as habilitações frente às demandas sociais da região (DCN, 2001). 


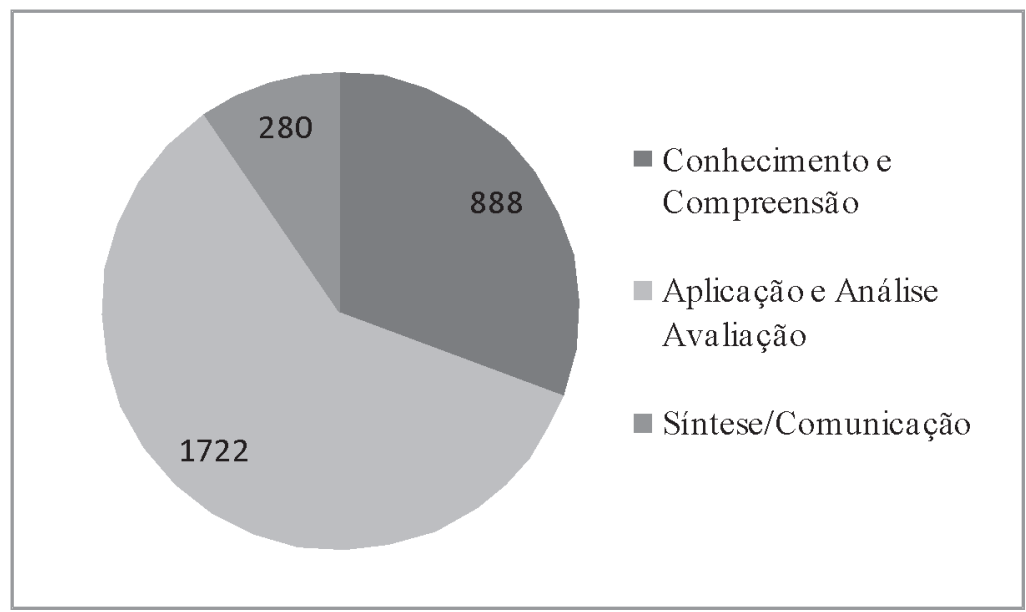

Apesar das recomendações o que percebemos, após a análise de todas as regiões, é que não há uma maior atenção voltada às características regionais. Estas estão representadas em pequenas manifestações isoladas e, que, portanto, não representaram, em média, uma força de conteúdo.

Essas manifestações podem ser constatadas na lista de todas as disciplinas que têm alguma abordagem regional, são elas: Comunicação Alagoana; Folclore Brasileiro; Meio Ambiente e Turismo; Estágio em Saúde da Família e da Comunidade. Há ainda o registro das disciplinas de História Regional, Cultura Regional, Economia Regional e Realidade Socioeconômica e Política Regional, sendo que ao todo representaram vinte ocorrências.

A Região Norte é a que maior número de registros apresentou - um total de11 registros, sendo dois em Economia Regional, três em Realidade Regional, quatro em Cultura Regional e dois em História Regional. A região Nordeste registrou apenas a disciplina de Cultura Regional. A região Sudeste tem dois registros de Realidade Regional e um de Cultura Regional. Por fim, a região Sul apresenta três ocorrências em Realidade Regional e um em História Regional.

Com essa incidência pudemos concluir que a regionalização ainda não é uma tendência nas matrizes curriculares dos cursos analisados, em nenhuma das regiões e, portanto refletido na con- 
solidação da matriz nacional. Essa realidade pode ser observada no retrato nacional da estrutura curricular dos cursos de jornalismo que apresenta a seguinte configuração:

\begin{tabular}{|c|c|}
\hline DISCIPLINA & CARGA HORÁRIA/HORAS-AULA \\
\hline Filosofia & de 60 a 72 \\
\hline Sociologia da Comunicação & de 60 a 72 \\
\hline Antropologia Cultural & de 60 a 72 \\
\hline Psicologia da Comunicação & de 60 a 72 \\
\hline Economia Geral & de 60 a 72 \\
\hline Realidade Socioeconômica/Político & de 60 a 72 \\
\hline Estética, Comunicação e Cultura & de 60 a 72 \\
\hline Legislação e Ética Junto & de 60 a 72 \\
\hline Língua Portuguesa e Laboratório de Texto & acima de 100 \\
\hline Teoria da Comunicação & de 60 a 72 \\
\hline Introdução ao Jornalismo & de 80 a 92 \\
\hline História da Comunicação & de 60 a 72 \\
\hline Metodologia Científica e de Comunicação & acima de 100 \\
\hline Fotografia e Fotojornalismo & acima de 100 \\
\hline Planejamento Gráfico & acima de 100 \\
\hline Técnicas de Reportagem e Entrevista & acima de 100 \\
\hline Assessoria de Comunicação & de 80 a 92 \\
\hline Jornalismo Impresso & acima de 100 \\
\hline Redação Jornalística & acima de 100 \\
\hline Radiojornalismo & acima de 100 \\
\hline Telejornalismo & acima de 100 \\
\hline Jornalismo On Line & acima de 100 \\
\hline Projeto Experimental & acima de 200 \\
\hline Duas ou mais Especializações & acima de 100 \\
\hline Administração em Jornalismo/Comunicação & de 60 a 72 \\
\hline Cinema & de 60 a 72 \\
\hline Seminários em Comunicação/Tópicos Especiais & de 60 a 72 \\
\hline
\end{tabular}


A estrutura curricular nacional aproxima-se muito do currículo ministrado na região Sudeste do país, até por esta região apresentar o maior número de habilitações em Jornalismo do Brasil.

Os problemas identificados em outras regiões e, mais especificamente na região Sudeste, se repetem na matriz consolidada. Além da ausência de uma atenção às características regionais, como visto, constata-se a ausência do estágio supervisionado. Apesar da Federação Nacional de Jornalistas, FENAJ, manter um Programa de Estágio $^{6}$, não visualizamos essa adesão na estrutura curricular.

Ao todo, apenas 13 cursos em todo o país oferecem o estágio supervisionado em suas matrizes curriculares. $\mathrm{O}$ nordeste é a região que tem o maior número de cursos com estágio, com quatro registros. Sabemos que a proibição ao estágio é o grande responsável por esta ausência, todavia, atualmente está previsto pelas DCN,

[...] a existência de um programa de estágio orientado por objetivos de Ensino, Pesquisa e Extensão e que seja regulamentado e fiscalizado com a participação dos Sindicatos representativos dos setores profissionais pertinentes com jurisdição na região, para evitar o aviltamento do mercado de trabalho (DCN, 2001).

A estrutura curricular nacional, que tem em média 2890 horas-aula, está dividida da seguinte forma:

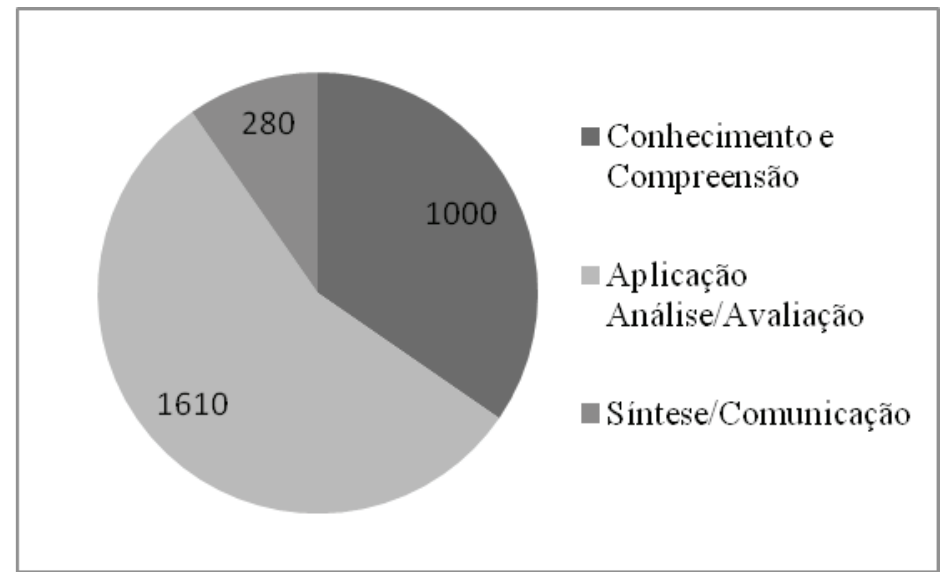

\footnotetext{
${ }^{6}$ Disponível no endereço http://www.fenaj.org.br/educacao/programa_estagio_jornalismo.pdf
} 
As disciplinas voltadas para a prática sobrepõem o Conhecimento e Compreensão e a Síntese em mais de 50\%. O mais grave é que, assim como na análise de cada região, não há um equilíbrio com a Síntese ou um espaço para uma integração entre teoria e prática. Também não há um local destinado, nas estruturas, para uma crítica à mídia, reflexão imprescindível para que possamos criar um vínculo franco com o mercado de trabalho e não ficarmos com as estruturas curriculares a mercê do que o mercado considera bom ou ruim.

A preocupação com a integração teoria/prática já está presente nas discussões acerca do ensino de comunicação muito antes das DCN e nas próprias premissas que a nortearam já constava o registro de que não havia correlação entre as formações teóricas e a parte geral do Curso e nem entre a formação técnico-profissional e a parte habilitacional (DCN,2001).

Apesar da preocupação expressa, percebe-se, por meio da análise das matrizes curriculares, que ainda não se conseguiu solucionar essa questão. As DCN realmente dão esta possibilidade, mas ao contrário do que os especialistas responsáveis por sua elaboração, assim como da grande maioria das representações da sociedade civil ${ }^{7}$ que participaram das discussões que resultaram no texto final, as matrizes curriculares de jornalismo ainda estão "presas" a estrutura do Currículo Mínimo ${ }^{8}$, agora já não mais por força de lei. Essa análise foi efetuada em outra fase desta pesquisa (ainda de publicação inédita) que compara as estruturas curriculares apresentadas em cada região e depois consolidadas em uma matriz nacional ao elenco de disciplinas que compunham o Currículo Mínimo.

\section{Referências}

BLOOM, Benjamin S. Taxionomia de objetivos educacionais. Tradução de Flávia Maria Sant’Ana. Porto Alegre: Globo, 1974.

BERNARDO, Cristiane H.C. Educação jornalística: entre a cruz da academia e a espada do mercado, 2010. Tese (Doutorado) - Universidade Federal do Mato Grosso do Sul, Campo Grande.

\footnotetext{
${ }^{7}$ Com destaque para o Intercom; Enecos; Fórum de Professores de Jornalismo; Fenaj. 8 Trata-se do último currículo mínimo que vigorou até as DCN serem aprovadas (Resolução 02/84 do CNE).
} 
CÂMARA DE EDUCAÇÃO SUPERIOR - CES/CNE. Parecer 1.363/01 CES (aprovado em 12/12/2001). Retificação do Parecer CNE/CES 492/2001. Brasília: CNE, 2001.

CONSELHO NACIONAL DE EDUCAÇÃO. Novo currículo de comunicação social. Resolução 02/84, 24/01/84. Brasília: Distrito Federal, 1984. ia Universidade Católica do Paraná MARQUES DE MELO, José. Comunicação e modernidade: o ensino e a pesquisa nas escolas de comunicação. São Paulo: Loyola, 1991.

. Contribuições para uma pedagogia da comunicação. São Paulo: Ed. Paulinas, 1974 (Comunicação Social, v.2).

MEDITSCH, Eduardo. Crescer para os lados ou crescer para cima: o dilema histórico do campo acadêmico do jornalismo. Disponível em: $<$ http://bocc. ubi.pt/pag/_texto.php?html2=meditsch-eduardo-dilema-historico-jornalismo. html>. Acesso em: 15 st. 2007.

MOURA, Cláudia Peixoto de. O curso de comunicação social no Brasil: do currículo mínimo às novas diretrizes curriculares. Porto Alegre: EDIPUCRS, 2002.

SCHUCH, Hélio A. Adequação do ensino na formação de jornalistas. Intercom: Revista Brasileira de Ciências da Comunicação, São Paulo, v.25, no.1, p.87-106, jan./jun. 2002.

SILVA, C. E. L. O adiantado da hora: a influência americana Sobre o jornalismo brasileiro. São Paulo: Summus, 1991.

COELHO SOBRINHO, José. Do que somos capazes!: relato de uma experiência pedagógica, 2001. Tese (Livre-Docência em Comunicação) - Universidade de São Paulo.

VALVERDE, Franklin L. O papel pedagógico do estágio na formação do jornalista, 2006. Tese (Doutorado em Comunicação) - Universidade de São Paulo.

ZANETIN, Roseli P. Poder, cultura e IES particulares: desempenho e comunicação, 2006. Tese (Doutorado em Comunicação) - Universidade de São Paulo.

Sites:

http://www.eca.usp.br/prof/moran/uber.htm

http://www.educacaosuperior.inep.gov.br/funcional/busca_curso.stm http://www.fenaj.org.br/educacao/programa_estagio_jornalismo.pdf

Recebido: 11.9 .2011

Aceito: 15.4.2012 